\title{
REGIME TÉRMICO E HÍDRICO DO SOLO PARA ÁREA DE FLORESTA TROPICAL EM ANOS DE EL NIÑO E LA NIÑA, CAXIUANÃ-PA: ESTUDO DE CASO
}

\author{
SERGIO RODRIGO QUADROS DOS SANTOS ${ }^{1}$, ROMMEL BENICIO COSTA DA SILVA ${ }^{2}$, PRISCILLA \\ NASCIMENTO BARRETO ${ }^{3}$, HILDO GIUSEPPE G. C. NUNES ${ }^{4}$, RONALDO DA SILVA RODRIGUES ${ }^{4}$, \\ THAMIRIS LUISA DE OLIVEIRA BRADÃO CAMPOS ${ }^{5}$.
}

\author{
${ }^{1}$ Universidade Federal de Campina Grande (UFCG), Campina Grande, PB, Brasil, \\ ${ }^{2}$ Universidade de São Paulo (USP), São Paulo, SP, Brasil, \\ ${ }^{3}$ Universidade Federal do Pará (UFPA), Belém, PA, Brasil \\ ${ }^{4}$ Universidade Federal Rural da Amazônia (UFRA), Belém, PA, Brasil, \\ ${ }^{5}$ Universidade Federal do Rio de Janeiro (UFRJ), Rio de Janeiro, RJ, Brasil
}

sergiosanntos@yahoo.com.br, rbcsilva@model.iag.usp.br, prislla_nb@yahoo.com.br, garibalde13@gmail. com,ronald_ufo@yahoo.com.br, thamiris_brandao@yahoo.com.br

Recebido Maio 2010 - Aceito Novembro 2010

\begin{abstract}
RESUMO
Os regimes térmicos e hídricos do solo se comportam de maneiras diferentes em anos de ocorrência dos fenômenos El Niño, La niña e ano de não ocorrência de nenhum dos dois fenômenos. Para estudar estes comportamentos utilizou-se dados de totais horários e mensais da precipitação pluviométrica, dados médios horários e mensais da temperatura do solo nas profundidades de $2 \mathrm{~cm}$ e $10 \mathrm{~cm}$ e umidade do solo nas profundidades de $5 \mathrm{~cm}$ e $20 \mathrm{~cm}$, para os anos representativos dos eventos pesquisados. Os resultados mostram que o ano sob a influência do fenômeno El Niño, apresentou maiores valores de temperatura e menores valores de umidade do solo, quando comparado com o ano que esteve sob a influência do fenômeno La Niña. Por outro lado, o ano em que não houve ocorrência dos fenômenos La Niña e El Niño, apresentou valores de temperatura (umidade) do solo maiores (menores) do que o ano de La Niña, porém menores (maiores) do que no ano de El Niño.

Palavras-chave: Perfis de temperatura e umidade, ENOS, Floresta
\end{abstract}

\begin{abstract}
THERMAL AND HYDROLOGIC REGIME TO SOIL AT TROPICAL FOREST AREA INYEAR OF EL NIÑO AND LA NIÑA, CAXIUANÃ-PA: A CASE STUDY.

The thermal and hydrologic regime to soil if behave differently in years of occurrence of El Niño, La Niña and that non-occurrence about both (El Niño and La Niña). To study these behaviors, we used data of the hourly total and monthly of rainfall, average hourly and monthly data of soil temperature at depths of $2 \mathrm{~cm}$ and $10 \mathrm{~cm}$ and soil moisture at depths of $5 \mathrm{~cm}$ and $20 \mathrm{~cm}$, for years the events searched. The results show that the year was about the influence of El Niño had higher temperature and lower values of soil moisture when compared with the year that was on the influence of La Niña. On the other hand the years that there is no occurrence of the phenomena El Niño and La Niña, showed values of soil temperature (moisture) higher (smaller) than the La Niña year, but smaller (higher) than the year of El Niño
\end{abstract}

Keywords: Temperature and moisture profiles, ENSO, Forest 


\section{INTRODUÇÃO}

A Amazônia é a maior floresta tropical úmida do mundo, com uma área total de aproximadamente 7 milhões de $\mathrm{km}^{2}$, o que representa cerca de $56 \%$ das florestas tropicais da Terra. A floresta é cortada pelo rio Amazonas e seus afluentes, representando a maior rede fluvial do globo, e respondendo por aproximadamente $20 \%$ do total de água doce despejado nos oceanos do planeta (Correia et al., 2007). A precipitação pluviométrica é um dos principais elementos climatológicos na região, pois além de constituir a fase aérea do ciclo hidrológico, influência no comportamento de outras variáveis meteorológicas como temperatura, vento e umidade, é a que melhor caracteriza a variabilidade climática na região (Marengo e Hastenrath, 1993). Sua variabilidade espacial e temporal é modulada por sistemas dinâmicos de microescala, mesoescala e grande escala. Dentre os sistemas de grande-escala atuantes nessa modulação, destacam-se o ciclo ENOS (El Niño/ Oscilação Sul), ele apresenta duas fases extremas conhecidas El Niño e La Niña. As condições do El Niño associam-se ao aquecimento anômalo em grande-escala nas águas oceânicas sobre o Pacífico Equatorial centro-leste. Inversamente a La Niña relaciona-se ao resfriamento anormal das águas oceânicas equatoriais sobre a bacia centro-leste (Trenberth, 1997). Os fenômenos ENOS provocam mudanças significativas nas circulações de Walker e Hadley, de modo que, no El Niño/La Niña observa-se a predominância de anomalias de vento descendente (ascendente) na região, o que resulta na inibição (intensificação) da convecção, e conseqüentemente, contribuem na variabilidade do regime pluviométrico da região Amazônica (Souza et al., 2000).

As anomalias climáticas mais conhecidas são as relacionadas com o regime das chuvas, embora o regime térmico e hídrico também possa ser modificado. O estudo térmico e hídrico do solo, bem como, a sua variabilidade espacial e temporal, se torna ainda mais importante na medida em que a situação natural dos ecossistemas é perturbada por mudanças feitas pelo ser humano, pois os solos participam de todo o processo de troca de água e energia entre superfície, biota e a atmosfera. Nos processos de interação solo-atmosfera, os perfis de temperatura e umidade do solo dependem entre outros fatores, das características físicas dos mesmos e das trocas de calor e vapor d'água com a atmosfera, que por sua vez dependem do clima e da cobertura vegetal local. Os comportamentos térmicos e hídricos do solo, naturalmente apresentam variações devido ao fluxo diário de radiação solar incidente na superfície, dos eventos de chuva e das variações sazonais e anuais dessas variáveis meteorológicas (Souza et al., 2002). O estudo e monitoramento da temperatura e umidade do solo possuem relevância nos estudos agrometeorológicos, através da disponibilidade hídrica para culturas, e também tem igual importância para estudos micrometeorológicos e ambientais em geral (Costa et al., 2004).

Este trabalho tem como objetivo estudar o regime térmico e hídrico do solo em anos de ocorrência dos fenômenos El Niño e La Niña, e ano de não ocorrência de nenhum dos dois fenômenos, considerado para este estudo como ano neutro na Floresta Nacional de Caxiuanã - PA, com a finalidade de quantificar a influência dos fenômenos El Niño e La Niña no regime térmico e hídrico do solo.

\section{DADOS E METODOLOGIA}

A área em estudo está localizada na Floresta Nacional de Caxiuanã (Figura 1), distante em torno de $400 \mathrm{~km}$ de Belém, no município de Melgaço-Pa. Essa Floresta é constituída, em $85 \%$ de sua área, por floresta densa de terra firme, com dossel médio das árvores entre 30 e $40 \mathrm{~m}$ de altura, as quais, entretanto só interceptam pouco mais de $10 \%$ da precipitação incidente (Moraes, et al., 1997). Segundo Ruivo et al. (2000), na região predominam solos classificados como Latossolos, que variam de bem a moderadamente drenados, cor bruno-amarelo-escuro a vermelho-amarelado; a textura varia de arenosa à argilosa.

Para este estudo foram utilizados dados totais de precipitação na escala horária e mensal, já para a temperatura e umidade do solo utilizou-se, respectivamente, as médias horárias e mensais nas profundidades de $2 \mathrm{~cm}$ e $10 \mathrm{~cm}$ e $5 \mathrm{~cm}$ e $20 \mathrm{~cm}$, para os anos de 2006, 2007 e 2008. Para a aquisição destes dados utilizou-se os seguintes sensores, CSI107-L12 responsável pela medição de temperatura do solo, CS616-L50 que mede a umidade do solo e o pluviógrafo TB4-L RAIN GAUGE. Esses sensores são de baixa freqüência e estão conectados a um datalogger modelo CR10X (Campbell Scientific), os quais fazem parte de uma estação meteorológica automatizada,

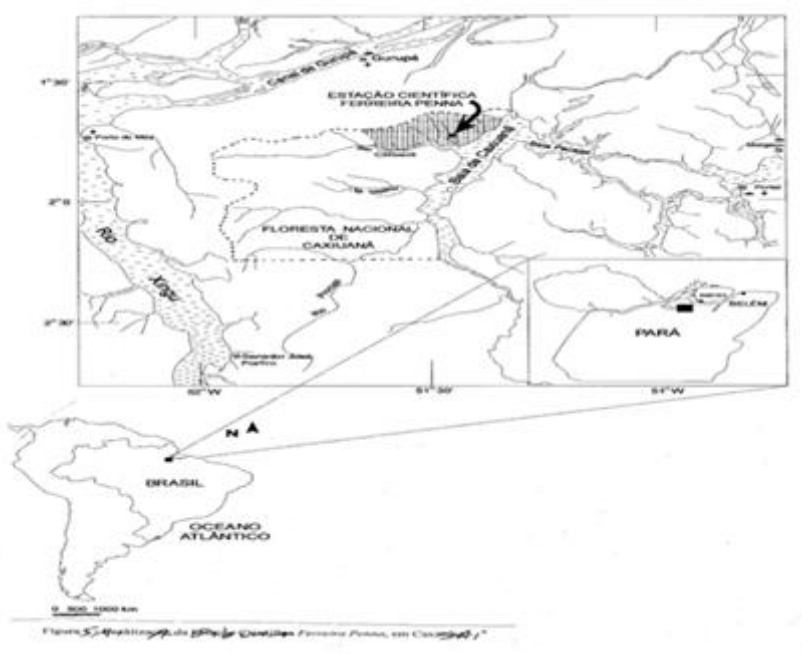

Figura1 - Localização da Floresta Nacional de Caxiuanã. 
que esta instalada em uma torre micrometeorológica de $52 \mathrm{~m}$ de altura. Os dados são coletados em campanhas mensais e registrados a cada 30 minutos, em seguida são tratados e encaminhados a um banco de dados.

A torre micrometeorológica e todos os seus sensores pertencem ao Programa LBA (Large Scale BiosphereAtmosphere in Amazon Program), o qual envolve pesquisas interdisciplinares sobre o funcionamento da Amazônia como entidade regional, com respeito aos ciclos da água, carbono, gases do efeito estufa e nutrientes; e como as alterações dos usos da terra e do clima afetam o funcionamento biológico, físico e químico dos ecossistemas amazônicos. Também foram consultadas informações sobre a TSM (Temperatura da Superfície do Mar) do oceano Pacífico Oriental no Centro de Previsão de Tempo e Estudos Climáticos (CPTEC), para verificar os anos de ocorrência dos fenômenos El Niño e La Niña, desta forma constatou-se que o ano de 2006 foi caracterizado como ano de El Niño (anomalia positiva de TSM), 2007 como ano neutro (padrões de neutralidade de TSM) e 2008 ano de La Niña (anomalia negativa de TSM).

\section{RESULTADOS E DISCUSSÕES}

\subsection{Precipitação pluviométrica}

Para o ano de 2006 (El Niño) verificou-se que $611 \mathrm{~mm}$ (43\%) do total da precipitação ocorrem no período diurno da estação chuvosa e $804 \mathrm{~mm}$ (57\%) ocorrem no período noturno, na estação menos chuvosa $152 \mathrm{~mm}$ (37\%) das chuvas ocorrem no

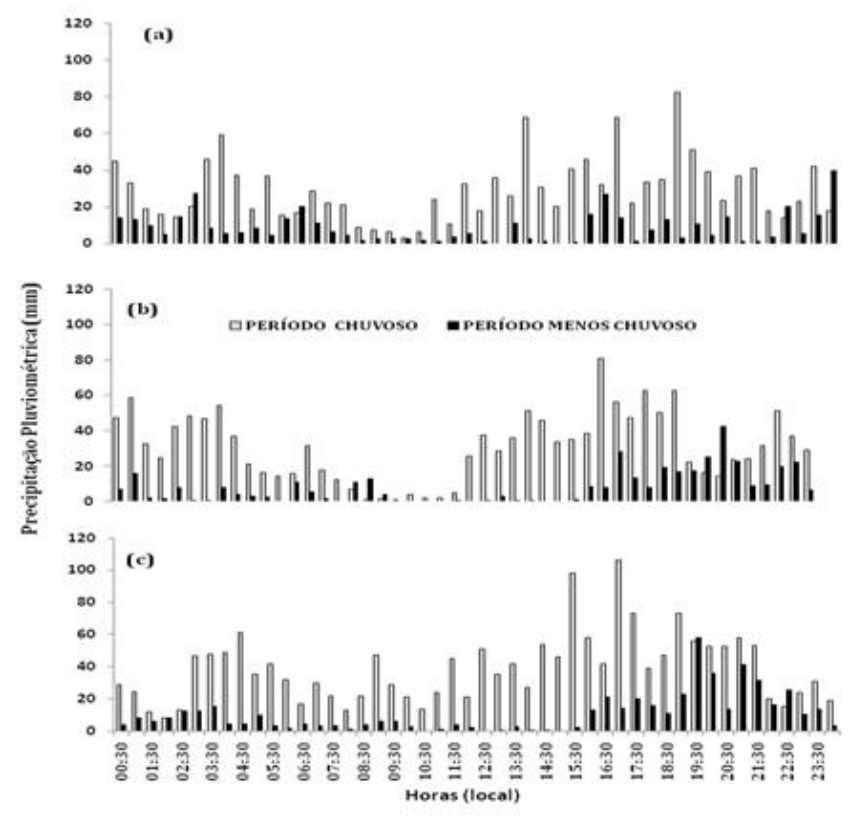

Figura 2 - Variação temporal da precipitação pluviométrica na Flona de Caxiuanã nos anos de 2006 (a), 2007(b) e 2008(c). período diurno e $256 \mathrm{~mm}$ (63\%) no período noturno (Figura 2a). Em 2007 (neutro) a estação chuvosa apresenta 587mm (39\%) de chuva no período diurno e $904 \mathrm{~mm}$ (61\%) no período noturno, já na estação menos chuvosa $99 \mathrm{~mm}$ (26\%) das chuvas ocorrem no período diurno e $286 \mathrm{~mm}$ (74\%) no período noturno (Figura 2b). Em 2008 (La Niña) durante a estação chuvosa, $968 \mathrm{~mm}$ $(52 \%)$ das chuvas ocorrem no período diurno e $910 \mathrm{~mm}(48 \%)$ no período noturno, já na estação menos chuvosa $108 \mathrm{~mm}$ (22\%) do total pluviométrico ocorrem no período diurno e $380 \mathrm{~mm}$ (78\%) no período noturno (Figura 2c). Constata-se que no ano de ocorrência do fenômeno La Niña há mais precipitação do que no ano de influência do fenômeno El Niño. Segundo Souza et al. (2000), a influência do fenômeno La Niña tende a favorecer a precipitação na Região Amazônica e o El Niño tende a inibir a mesma.

Vale ressaltar ainda que durante a estação chuvosa há distribuição mais homogênea do volume pluviométrico no ciclo diurno, ocorrendo precipitações em quase todos os horários, enquanto que na estação menos chuvosa a predominância das chuvas é no período noturno. De acordo com Souza Filho et al. (2006), na estação menos chuvosa essa predominância das chuvas no período noturno é devido à convecção diurna resultante do aquecimento da superfície. Os estudos de Molion (1987) e Fisch et al., (1996) mostram que na estação chuvosa somente as precipitações que ocorrem no final da tarde, entre $17 \mathrm{~h}$ e $18 \mathrm{~h}$ local, são causadas por intensos sistemas convectivos, enquanto que no restante do dia são influenciados por sistemas de grande escala como a zona de convergência intertropical (ZCIT).

A variabilidade temporal da precipitação na região apresenta dois períodos distintos, um de maior pluviosidade que compreende os meses de Dezembro a Maio, estação chuvosa; e um de menor pluviosidade de Junho a Novembro, estação menos chuvosa, este resultado é similar ao encontrado por Costa (2006). O total pluviométrico anual para o ano de 2006 (El Niño) foi de $1.223 \mathrm{~mm}$, sendo que o mês mais chuvoso

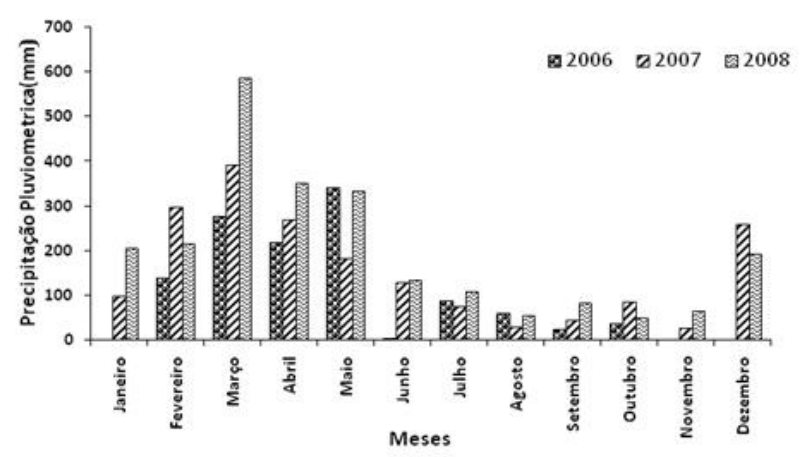

Figura 3 - Variação total mensal da precipitação pluviométrica na FLONA de Caxiuanã nos anos de 2006, 2007 e 2008. 
foi Março com 276mm e o menos chuvoso foi Setembro com $22 \mathrm{~mm}$, apresentando assim uma redução aproximada de $92 \%$ da precipitação. O ano de 2007 (neutro) apresenta um total de precipitação pluviométrica de $1.878 \mathrm{~mm}$, o mês de maior pluviosidade foi Março com 391mm e o de menor pluviosidade foi Novembro com $26 \mathrm{~mm}$, apresentando uma redução aproximada de $93 \%$ da precipitação. Em 2008 (La Niña) o total pluviométrico foi de $2.367 \mathrm{~mm}$, o mês mais chuvoso foi Março com $585 \mathrm{~mm}$ e o menos chuvoso foi Outubro com $84 \mathrm{~mm}$, a redução da precipitação entre os meses mais e menos chuvosos foi de aproximadamente $92 \%$ (Figura 3). Desta forma, os totais mensais de precipitação, do ano de 2007, são bem maiores do que o ano em que há influência do fenômeno El Niño e menores no ano de ocorrência do fenômeno La Niña. De acordo com os estudos de Souza et al.,(2000), em anos de El Niño, ocorre o aquecimento anormal do Pacífico Tropical Leste, juntamente com o enfraquecimento dos ventos alísios na região equatorial, alterando os padrões de transporte de umidade. Desse modo, há redução da precipitação na região, enquanto que os anos de ocorrência do Fenômeno La Niña apresentam configuração inversa, com intensificação do regime de Precipitação. O estudo de Costa (2006) mostra que a deficiência da água, provocada pela exclusão de $95 \%$ da precipitação em uma área de floresta

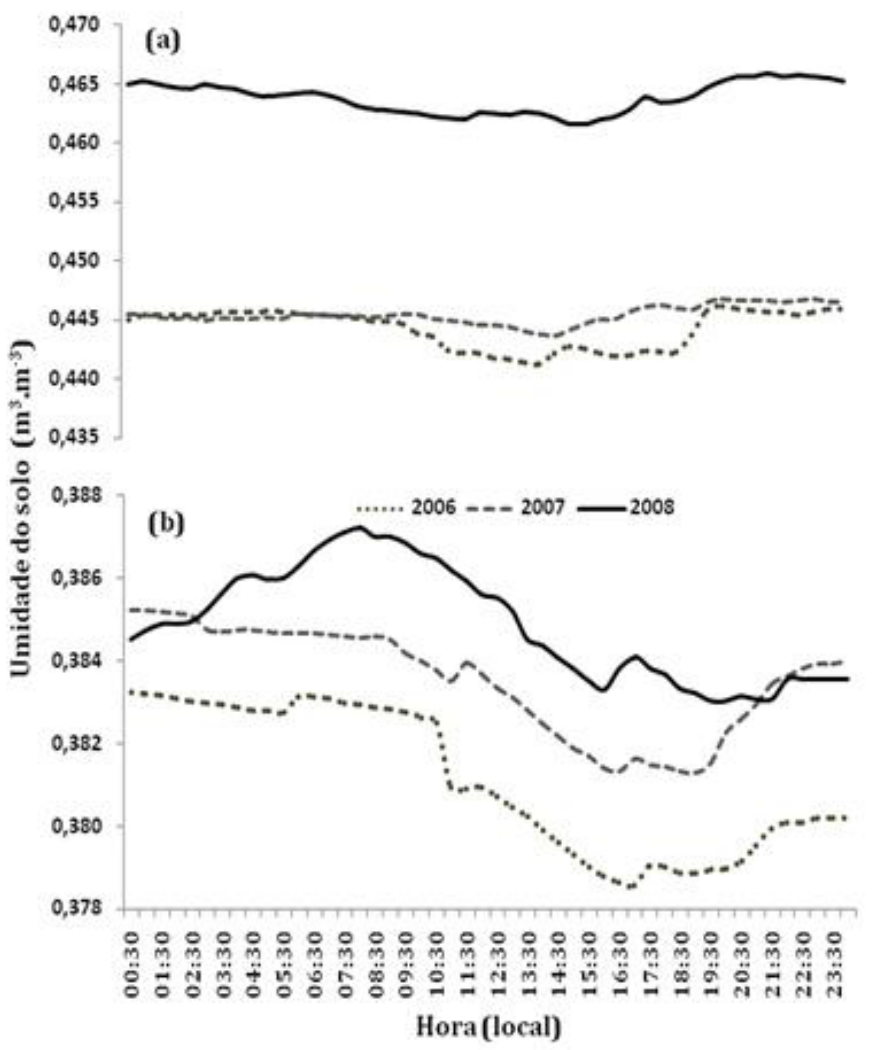

Figura 4 - Variação media horaria da umidade do solo em $5 \mathrm{~cm}$ de profundidade na estação chuvosa (a) e estação menos chuvosa (b), para os anos de 2006, 2007 e 2008. tropical chuvosa, proporcionou a variabilidade sazonal de todos os elementos hidrometeorológicos estudados, e esta exclusão contribuiu para alterações na microfauna local.

\subsection{UMIDADE DO SOLO}

A umidade do solo é um elemento importande, pois regula as atividades dos organismos e limita a distribuição dos mesmo dentro de um ecossistema (Odum, 1988). As variações horárias da umidade do solo, na camada superficial $(5 \mathrm{~cm})$ durante a estação chuvosa (Figura 4a), apresentou valores máximos de $0,446 \mathrm{~m}^{3} \cdot \mathrm{m}^{-3}$ às $6: 00 \mathrm{~h}$ em $2006,0,447 \mathrm{~m}^{3} \cdot \mathrm{m}^{-3}$ às $7: 00 \mathrm{~h}$ em 2007 e $0,464 \mathrm{~m}^{3} \cdot \mathrm{m}^{-3}$ às $5: 00 \mathrm{~h}$ em 2008 e valores mínimos de $0,441 \mathrm{~m}^{3} \cdot \mathrm{m}^{-3}$ às $13: 30 \mathrm{~h}$ em $2006,0,444 \mathrm{~m}^{3} \cdot \mathrm{m}^{-3}$ às $14: 30 \mathrm{~h}$ em $2007 \mathrm{e} 0,462 \mathrm{~m}^{3} \cdot \mathrm{m}^{-3}$ às $12: 00 \mathrm{~h}$ em $2008 . \mathrm{Na}$ estação menos chuvosa (Figura $4 \mathrm{~b}$ ) os valores máximos para a umidade do solo foram de $0,383 \mathrm{~m}^{3} . \mathrm{m}^{-3}$ às $5: 30 \mathrm{~h}$ em 2006 , $0,385 \mathrm{~m}^{3} \cdot \mathrm{m}^{-3}$ às $7: 00 \mathrm{~h}$ em 2007 e $0,387 \mathrm{~m}^{3} \cdot \mathrm{m}^{-3}$ às $6: 30 \mathrm{~h} \mathrm{em}$ 2008 e os valores mínimos foram de $0,379 \mathrm{~m}^{3} \cdot \mathrm{m}^{-3}$ às $15: 00 \mathrm{~h}$ em $2006,0,381 \mathrm{~m}^{3} \cdot \mathrm{m}^{-3}$ às $16: 00 \mathrm{~h}$ em 2007 e $0,383 \mathrm{~m}^{3} \cdot \mathrm{m}^{-3}$ às 15:30h em 2008. Esta variável apresentou valores maiores no período da manhã e da noite e menores no período da tarde. De acordo com Caldwell et al., (1998), a reposição da água no

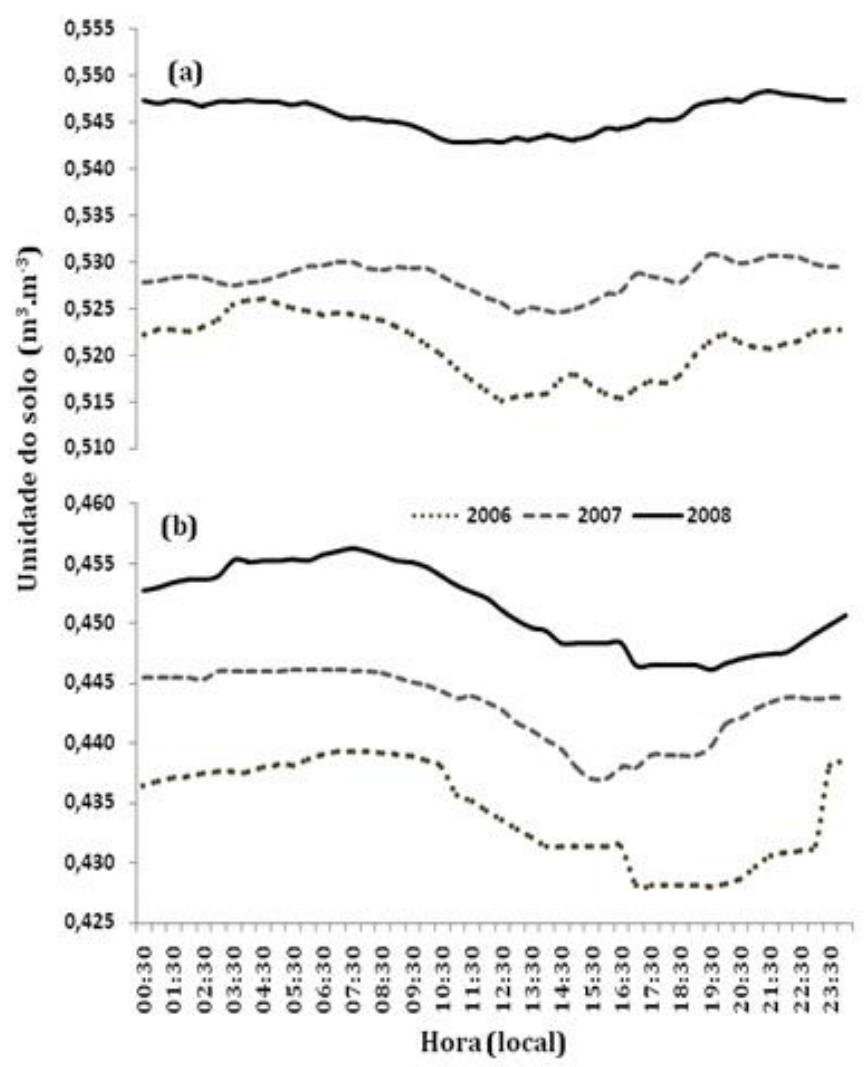

Figura 5 - Variação media horaria da umidade do solo em $5 \mathrm{~cm}$ de profundidade na estação chuvosa (a) e estação menos chuvosa (b), para os anos de 2006, 2007 e 2008. 
solo ocorre no período da manhã e da noite, através do sistema radicular das plantas, onde ocorre um processo conhecido como "elevador hidráulico", este processo acontece, pois durante o período da tarde o conteúdo de água que está presente na camada superficial do solo é usado na evapotranspiração. Desta forma, essa reposição é importante, pois ajuda as árvores a evitar estresse hídrico e aumenta a eficiência das raízes profundas sem extrair água.

A variação da umidade do solo na camada mais profunda, $20 \mathrm{~cm}$, apresenta na estação chuvosa (Figura 5a) valores máximos de $0,526 \mathrm{~m}^{3} \cdot \mathrm{m}^{-3}$ às $5: 00 \mathrm{~h}$ em 2006 , $0,530 \mathrm{~m}^{3} \cdot \mathrm{m}^{-3}$ às $6: 30 \mathrm{~h}$ em $2007 \mathrm{e} 0,547 \mathrm{~m}^{3} \cdot \mathrm{m}^{-3}$ às $6: 00 \mathrm{~h} \mathrm{em}$ 2008 e valores mínimos de $0,515 \mathrm{~m}^{3} \cdot \mathrm{m}^{-3}$ às $12: 30 \mathrm{~h}$ em 2006 , $0,525 \mathrm{~m}^{3} \cdot \mathrm{m}^{-3}$ às $15: 00 \mathrm{~h}$ em $2007 \mathrm{e} 0,543 \mathrm{~m}^{3} \cdot \mathrm{m}^{-3}$ às $14: 30 \mathrm{~h}$ em 2008. Na estação menos chuvosa (Figura 5b) os valores máximos de umidade do solo foram de $0,439 \mathrm{~m}^{3} \cdot \mathrm{m}^{-3}$ às $6: 00 \mathrm{~h}$ em $2006,0,446 \mathrm{~m}^{3} \cdot \mathrm{m}^{-3}$ às $5: 30 \mathrm{~h}$ em $2007 \mathrm{e} 0,456 \mathrm{~m}^{3} \cdot \mathrm{m}^{-3}$ às 6:30h em 2008, os valores mínimos de umidade solo foram de $0,428 \mathrm{~m}^{3} \cdot \mathrm{m}^{-3}$ às $17: 00 \mathrm{~h} \mathrm{em} 2006,0,437 \mathrm{~m}^{3} \cdot \mathrm{m}^{-3}$ às $15: 30 \mathrm{~h} \mathrm{em}$ $2007 \mathrm{e} 0,446 \mathrm{~m}^{3} \cdot \mathrm{m}^{-3}$ às $17: 30 \mathrm{~h}$ em 2008 . Ocorreram maiores valores de umidade nesta camada do solo, quando comparadas com a camada superficial, em todos os anos, principalmente por ela apresentar baixos valores de temperatura do solo, outros fatores a serem citados que contribuem para esse aumento de umidade são: percolação da água por gravidade e a menor concentração de biomassa de raízes, pois segundo Nepstad et al., (1994), a maior concentração da mesma está nos primeiros centímetros do solo.

A média anual da umidade do solo em $5 \mathrm{~cm}$ foi de $0,410 \mathrm{~m}^{3} \cdot \mathrm{m}^{-3}$ em 2006, $0,413 \mathrm{~m}^{3} \cdot \mathrm{m}^{-3}$ em 2007 e $0,420 \mathrm{~m}^{3} \cdot \mathrm{m}^{-3}$ em 2008. Os valores máximos de umidade do solo na camada

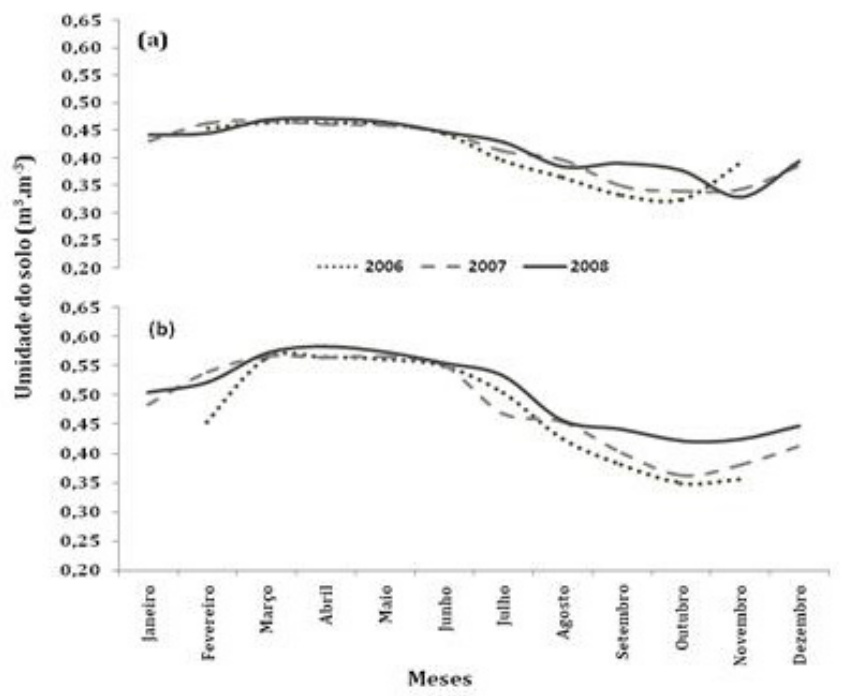

Figura 6 - Variação media anual da umidade do solo em $5 \mathrm{~cm}$ (a) e $20 \mathrm{~cm}$ (b) de profundidade, para os anos de 2006, 2007 e 2008. superficial foram de $0,464 \mathrm{~m}^{3} \cdot \mathrm{m}^{-3}$ em Março de $2006,0,468 \mathrm{~m}^{3} \cdot \mathrm{m}^{-3}$ em Março de 2007 e $0,47 \mathrm{~m}^{3} \cdot \mathrm{m}^{-3}$ em Abril de 2008 e os valores mínimos registrados foram de $0,325 \mathrm{~m}^{3} \cdot \mathrm{m}^{-3}$ em Outubro de 2006, $0,340 \mathrm{~m}^{3} \cdot \mathrm{m}^{-3}$ em Outubro de 2007 e $0,329 \mathrm{~m}^{3} \cdot \mathrm{m}^{-3} \mathrm{em}$ Novembro de 2008, (Figura 6a). Em 20cm de profundidade as medias anuais foram de $0,471 \mathrm{~m}^{3} \cdot \mathrm{m}^{-3} \mathrm{em} 2006,0,475 \mathrm{~m}^{3} \cdot \mathrm{m}^{-3} \mathrm{em}$ $2007 \mathrm{e} 0,503 \mathrm{~m}^{3} \cdot \mathrm{m}^{-3} \mathrm{em} 2008$. Os valores máximos de umidade do solo aconteceram no mês de Março nos anos de 2006 com $0,564 \mathrm{~m}^{3} \cdot \mathrm{m}^{-3}$ e $2007 \mathrm{com} 0,567 \mathrm{~m}^{3} \cdot \mathrm{m}^{-3}$ e no ano de $2008 \mathrm{o}$ valor máximo foi registrado em Abril, com $0,583 \mathrm{~m}^{3} \cdot \mathrm{m}^{-3}$. Os valores mínimos de umidade nessa camada foram no mês de Outubro, com $0,349 \mathrm{~m}^{3} \cdot \mathrm{m}^{-3}$ em 2006 e $0,380 \mathrm{~m}^{3} \cdot \mathrm{m}^{-3}$ em 2007, no ano de 2008 o valor mínimo ocorreu no mês de Novembro com $0,422 \mathrm{~m}^{3} \cdot \mathrm{m}^{-3}$ (Figura 6b). Desta forma, o ano de 2008, que esteve sob influência do fenômeno La Niña, apresentou maiores valores de umidade no solo, já que a precipitação é a maior fonte de umidade do solo. Por outro lado, o ano de 2007, que não estave sob a influência dos fenômenos El Niño e La Niña, apresentou maiores valores de umidade do solo, quando comparado com o ano de 2006, que estave sob influência do fenômeno El Niño. O estudo de Clark e Clark (1994) mostra que a variabilidade no regime hídrico pode ocasionar alterações nas taxas de crescimento arbóreo e o de Nepstad et al., (1999) que a deficiência de água no solo leva à diminuição gradual da fotossíntese pela maior resistência à fixação do $\mathrm{CO}_{2}$ por causa do fechamento dos estômatos.

\subsection{TEMPERATURA DO SOLO}

As variações das temperaturas do ar e do solo são fundamentais para o desenvolvimento e sobrevivência das espécies vegetais e animais que vivem no interior das florestas, sendo esta uma variável de extrema importância, tendo influência direta na evapotranspiração e nos processos de troca de energia (Oliveira et al., 2002).

Durante a estação chuvosa a camada superficial do solo $(2 \mathrm{~cm})$ apresentou valores de temperaturas mínima de $28,4^{\circ} \mathrm{C}$ às $6: 00 \mathrm{~h} \mathrm{em} 2006,27,2^{\circ} \mathrm{C}$ às $7: 30 \mathrm{~h} \mathrm{em} 2007 \mathrm{e} 26,9^{\circ} \mathrm{C}$ às $8: 30 \mathrm{~h} \mathrm{em}$ 2008 , e os valores máximos de temperatura foram de $29,1^{\circ} \mathrm{C}$ às $15: 00 \mathrm{~h}$ em $2006,27,5^{\circ} \mathrm{C}$ às $16: 30 \mathrm{~h}$ em 2007 e $27,2^{\circ} \mathrm{C}$ as $17: 00 \mathrm{~h}$ em 2008 (Figura 7a). Na estação menos chuvosa os valores das temperaturas mínimas do solo foram de $28,6^{\circ} \mathrm{C}$ às $5: 30 \mathrm{~h}$ em $2006,27,4^{\circ} \mathrm{C}$ às $6: 30 \mathrm{~h}$ em 2007 e $27,2^{\circ} \mathrm{C}$ às $7: 30 \mathrm{~h}$ em 2008. As temperaturas máximas do solo foram de $29,4 \mathrm{C}^{\circ}$ às $15: 30 \mathrm{~h}$ em $2006,28,1^{\circ} \mathrm{C}$ às $9: 30 \mathrm{~h}$ em 2007 e $27,5^{\circ} \mathrm{C}$ às $10: 30 \mathrm{~h} \mathrm{em}$ 2008 (Figura 7b). Ocorreram menores valores de temperatura no período da manhã e maiores no período da tarde em ambas as estações, vale ressaltar que os valores máximos e mínimos de temperatura do solo são maiores na estação menos chuvosa do que na estação mais chuvosa. 
$\mathrm{Na}$ estação chuvosa, a camada mais profunda do solo $(10 \mathrm{~cm})$ apresentou um comportamento semelhante entre as curvas de temperaturas, com valores mínimos de $25^{\circ} \mathrm{C}$ às $8: 30 \mathrm{~h}$ em $2006,24,9^{\circ} \mathrm{C}$ às $7: 00 \mathrm{~h}$ em $2007 \mathrm{e} 24,6^{\circ} \mathrm{C}$ às $5: 30 \mathrm{~h}$ em $2008 \mathrm{e}$ os valores de temperaturas máximas registradas foram de $25,4^{\circ} \mathrm{C}$ às $15: 30 \mathrm{~h}$ em $2006,25,2^{\circ} \mathrm{C}$ às $17: 00 \mathrm{~h} \mathrm{em} 2007 \mathrm{e} 25^{\circ} \mathrm{C}$ às $14: 00$ em 2008 (Figura 8a). Por outro lado, na estação menos chuvosa os valores das temperaturas mínimas foram de $25,3^{\circ} \mathrm{C}$ às $6: 00 \mathrm{~h}$ em $2006,25,1^{\circ} \mathrm{C}$ às $8: 30 \mathrm{~h}$ em $2007 \mathrm{e} 24,9^{\circ} \mathrm{C}$ às $8: 00 \mathrm{~h}$ em 2008 , e os valores máximos foram de $25,5^{\circ} \mathrm{C}$ às $15: 00 \mathrm{~h} \mathrm{em} 2006,25,3^{\circ} \mathrm{C}$ às 16:00h em 2007 e $25,3^{\circ} \mathrm{C}$ às 17:30h em 2008 (Figura 8b). Em seus estudos Prevedello (1996) mostra que a capacidade de um solo em armazenar e transferir calor é determinada pelas suas propriedades térmicas e pelas condições meteorológicas do local, que, por sua vez influenciam todos os processos químicos, físicos e biológicos do solo. Desta forma, as temperaturas do solo, em ambas as profundidades, foram maiores no ano de 2006 e menores no ano de 2008, pois eles estavam sob influência do fenômeno El Niño e La Niña, respectivamente.

A média anual da temperatura do solo, em $2 \mathrm{~cm}$ de profundidade, foi de $28,8^{\circ} \mathrm{C}$ em $2006,27,4^{\circ} \mathrm{C}$ em 2007 e $27^{\circ} \mathrm{C}$ em 2008. Os mínimos valores de temperatura do solo foram de $28,7^{\circ} \mathrm{C}$ em Março de $2006,27^{\circ} \mathrm{C}$ em maio de 2007 e $26,5^{\circ} \mathrm{C}$ em abril de 2008 e os valores máximos foram registrados, especificamente, durante os meses de novembro com $29,5^{\circ} \mathrm{C}$ em 2006, 27, $7^{\circ} \mathrm{C}$ em 2007 e 27,4 ${ }^{\circ} \mathrm{C}$ em 2008 (Figura 9a).

Em $10 \mathrm{~cm}$ de profundidade, os valores das médias anuais foram de $27,3^{\circ} \mathrm{C}$ em $2006,25,4^{\circ} \mathrm{C}$ em 2007 e $25,2^{\circ} \mathrm{C}$ em 2008 . Os mínimos valores de temperatura do solo aconteceram no mês

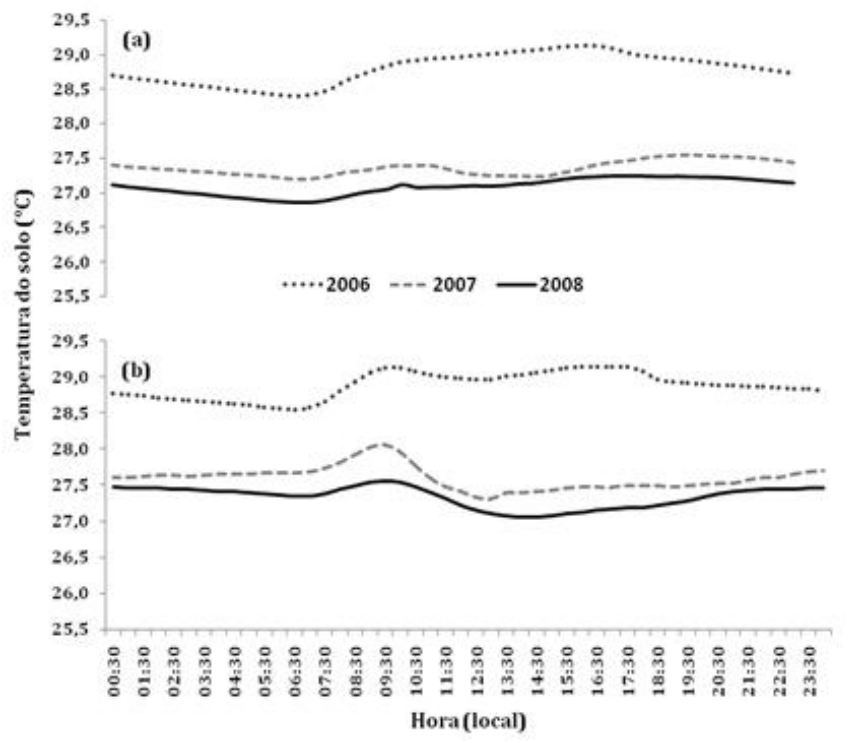

Figura 7 - Variação media horaria da temperatura do solo em $2 \mathrm{~cm}$ de profundidade na estação chuvosa (a) e estação menos chuvosa (b), para os anos de 2006, 2007 e 2008.

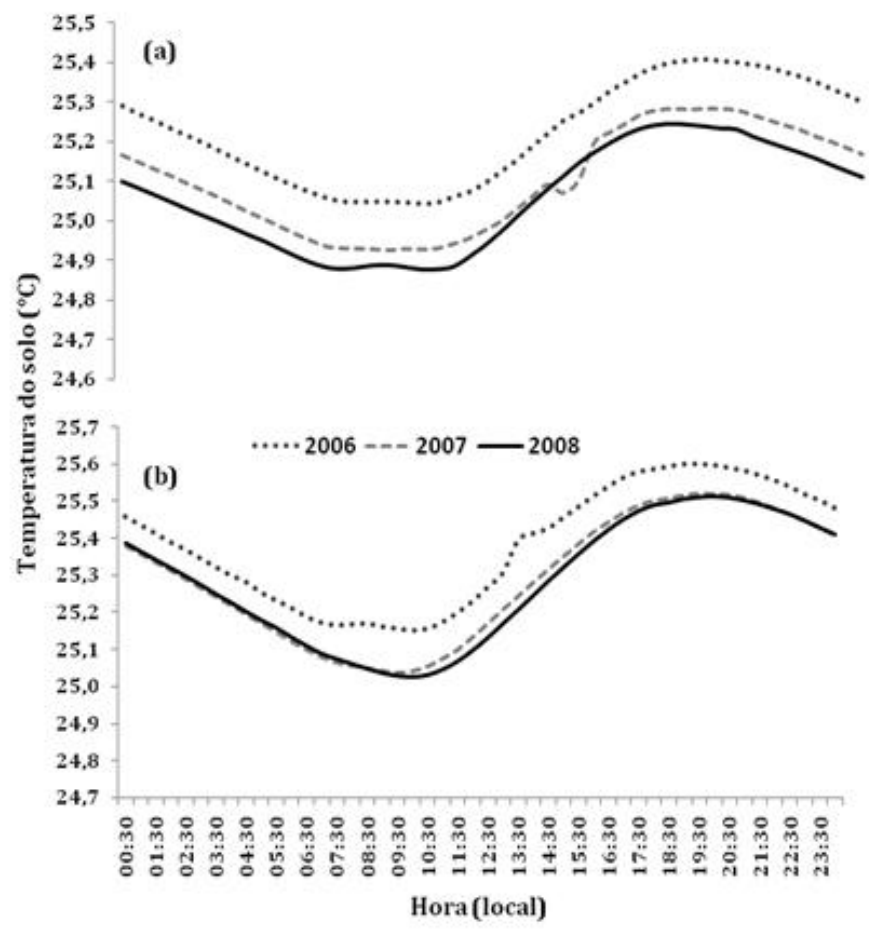

Figura 8 - Variação media horaria da temperatura do do solo em $10 \mathrm{~cm}$ de profundidade na estação chuvosa (a) e estação menos chuvosa (b), para os anos de 2006, 2007 e 2008.

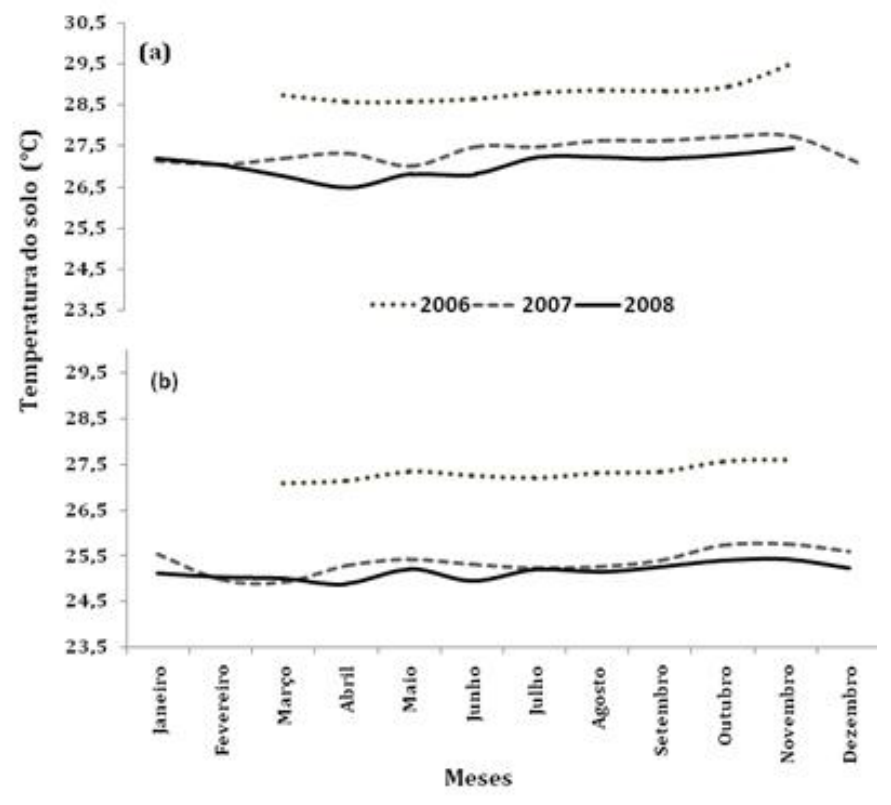

Figura 9 - Variação media anual da temperatura do solo em $2 \mathrm{~cm}$ (a) e $10 \mathrm{~cm}$ (b) de profundidade, para os anos de 2006, 2007 e 2008. 
de março com $27,1^{\circ} \mathrm{C}$ em 2006 e $24,9^{\circ} \mathrm{C}$ em 2007 , e no ano de 2008 o valor mínimo de temperatura do solo foi registrada em abril com $24,9^{\circ} \mathrm{C}$. Os máximos valores de temperatura nesta camada foram no mês de novembro com $27,6^{\circ} \mathrm{C}$ em 2006 , $25,8^{\circ} \mathrm{C}$ em 2007 e $25,4^{\circ} \mathrm{C}$ em 2008 (Figura 9b).

Desta forma, o ano de 2006 apresentou uma redução significativa da umidade do solo, neste mesmo ano as temperaturas do solo foram mais elevadas, pois toda energia que o solo absorvia era utilizada para aquecimento (calor sensível) do solo, no de 2008 o comportamento foi inverso, já que nesse mesmo ano notaram-se maiores valores de umidade e menores valores de temperatura do solo. $\mathrm{O}$ ano de 2007 apresentou valores de temperatura do solo maiores do que em 2008 e menores do que no ano de 2006, por que esse ano não esteve sob o efeito de condições climáticas adversas (El niño e La niña).

\section{CONCLUSÕES}

O ano de 2006, que esteve sob a influência do fenômeno El Niño, apresentou maiores valores de temperatura e menores valores de umidade do solo, quando comparado com o ano de 2008, que esteve sob a influência do fenômeno La Niña. Por outro lado, o ano em que não houve ocorrência dos fenômenos La Niña e El Niño, apresentou valores de temperatura do solo maiores do que o ano de La Niña, porém menores do que no ano de El Niño. Já, os valores de umidade do solo deste ano foram menores do que no ano de La Niña e maiores do que no ano de El Niño. Desta forma, ficou evidente que o regime térmico e hídrico do solo sofre a influência destes fenômenos.

\section{AGRADECIMENTOS}

Os autores agradecem ao Museu Paraense Emílio Goeldi, CNPq e ao IBAMA que proporcionaram as facilidades para o bom andamento da coleta de dados, ao Escritório Central do Programa LBA, pela utilização do espaço físico e cessão de membros da equipe do Programa LBA em Belém e a faculdade de Meteorologia da UFPA pelo apoio às atividades experimentais em Caxiuanã.

\section{REFERÊNCIAS BIBLIOGRÁFICAS}

CLARK, D.A.; CLARK, D.B. Climate - Induced Annual Variation in Canopy Tree Growth in Costa Rica Tropical Rain Forest Journal of Ecology, v. 82, p. 865 - 872, 1994. COSTA, A. C. L.; Braga, A. P.; FERREIRA DA COSTA, R.; GONÇALVES, P. H. L.; SILVA JUNIOR, J. A.; MEIR, P; MALHI, Y. (2004). Variações sazonais das temperaturas do ar e do solo sob influência de uma simulação de seca prolongada na floresta de Caxiuanã - ESECAFLOR. In:
XIII Congresso Brasileiro de Meteorologia, Fortaleza, 2004.

COSTA, A.C.L. Estudos Hidrometeorológicos em uma Floresta Tropical Chuvosa na Amazônia - Projeto ESECAFLOR. Revista Brasileira de Meteorologia, v. 21, n.3b. p. 283 $-290,2006$.

CALDWELL, M. M.; DAWSON, T. E. AND RICHARDS, J. H. Hydraulic lift: consequences of water efflux from the roots of plants. Oecologia 113:151-161, 1998.

CORREIA, F. W. ; CANDIDO, L. A. ; MANZI, A. O . Balanço de umidade na Amazônia e sua sensibilidade às mudanças na cobertura vegetal. Ciência e Cultura (SBPC) jcr, v. 59, p. 39-43, 2007.

FISCH, G., MARENGO, J., NOBRE, C. A. Clima da Amazônia climanalise-boletim de monitoramento e analise climática Edição Comemorativa de 10 anos,3 1996.

MARENGO, J.; HASTENRATH, S. Case studies of extreme climatic events in the Amazon Basin. Journal of Climate, v. 6, n. 4, p. 617-627, abr. 1993.

MOLIO, L. C. B.; climatologia dinâmica da região Amazônica: mecanismo de precipitação. Revista Brasileira de Meteorologia, v.2(1): 107-117,1987.

MORAES, J. C.; COSTA, J. P. R.; ROCHA, E. J. P.; SILVA, I. M. O. Estudos Hidrometeorologicos na Bacia do Rio Caxiuanã. Em: CAXIUANÃ. Ed. por Pedro L. B. Lisboa. Publicação do Museu Paraense Emilio Goeldi, MCT/ CNPq, Belém, PA, Brasil. pp 85-95, 1997.

NEPSTAD, D.C.; CARVALHO, C.R.; DAVIDSON, E.A.; JIPP, P.H LEVEBBRE, P.A.; NEGREIROS, G.H.; SILVE, E.D.; STONE, T.A.; TRUMBORE, S.E.; VIEIRA, S. The Role of Dup Roots in the Hydrological and Cycle of Carbon Amazonian Forest and Pasture. Nature, v. 372, p. $666-$ 669, 1994.

NEPSTAD, D. C.; VERISSIMO, A.; ALENCAR, A.; NOBRE, C.; LIMA, E.; LEFEBVRE,P.; SCHLESINGER,P.; POTTER, C.; MOUTINHO, P.; MENDOZA, E.; COCHRANE, M and V. BROOKS. Large-scale impoverishment of Amazonian forest by logging and fire. Nature, v.398, 505-508, 1999.

OLIVEIRA, M. C. F.; PEREIRA, M. G. P.; OLIVEIRA, J. B.; SOUZA, P. F. S.; COSTA, A. C. L; COSTA, J. P. R. Condições Ambientais e Micrometeorológicas do Ecossistema de Caxiuanã- PA. In: XII Congresso Brasileiro de Meteorologia, 2002, Foz do Iguaçu-PR, 2002.

ODUM, E. P. Ecologia, $\mathbf{1}^{\mathbf{a}}$ ed. Rio de Janeiro, RJ. Editora Guanabara. 434p. 1988.

PREVEDELLO, C. L. Física do solo com problemas resolvidos. Curitiba: Salesward-Discovery, 1996.

RUIVO, M. L. P.; QUANZ, B.; SALES, M. E. C.; MEIR, P. Solos dos sítios do experimento ESECAFLOR. In: LISBOA, P. L. B. (org.). Caixuanã: Populações tradicionais, meio 
físico \& diversidade biológica. Belém: Museu Paraense Emilio Goeldi, P.207-213. 2000.

SOUZA, E. B.; KAYANO, M. T.; TOTA, J; PEZZI, L; FISCH, G; NOBRE, C. On the influences of the El Niño, La Niña and atlantic dipole pattern on the Amazonian rainfall during 1960-1988. Acta Amazônica, v. 30, n. 2, p. 305-318, 2000.

SOUZA FILHO, J. D. C.; RIBEIRO, A.; COSTA, M. H; COHEN, J. C. P.; ROCHA, E. J. P. Variação sazonal do balanço de radiação em uma floresta tropical no nordeste da Amazônia. Revista Brasileira de Meteorologia, v.21, n. 3b, 318330, 2006.
SOUZA, J. R. S.; LOPES, Z. F.; COHEN, J. C. P.; COSTA, A. C. L. Variabilidade da temperatura e umidade em solos sob floresta, pastagem e manguezal, no leste da Amazônia. In: Anais do XII Congresso Brasileiro de Meteorologia. Foz do Iguaçu-PR, 2002.

TRENBERTH K. E. The definition of El Niño. Bulletin of the American Meteorological Society. v. 78, p. 2771-2777, 1997. 